\title{
O DISCURSO DOS PROFESSORES SOBRE A TRANSMISSÃO DA PEDICULOSE ANTES DE UMA ATIVIDADE EDUCATIVA
}

\author{
THE TEACHERS' DISCOURSE ON PEDICULOSIS TRANSMISSION \\ BEFORE AN EDUCATIONAL ACTIVITY
}

\author{
Pércide Verônica da Silva Cunha* \\ Zeneida Teixeira Pinto ** \\ Edson Ferreira Liberal *** \\ Júlio Vianna Barbosa ****
}

Cunha PVS, et al. O Discurso dos Professores Sobre a Transmissão da Pediculose Antes de uma Atividade Educativa. Rev Bras Crescimento Desenvolvimento Hum. 2008; 18(3): 298-307

\section{Resumo:}

A Pediculose é uma doença de importância para a saúde pública. Acredita-se que medidas educacionais colaborem para o sucesso do tratamento e da prevenção desta patologia. Este trabalho, realizado em escolas do Rio de Janeiro (RJ), Brasil, apresenta o discurso de professores de ensino fundamental sobre a forma como a Pediculose é transmitida. As informações foram obtidas através de entrevistas e analisadas pelo Discurso do Sujeito Coletivo. Revelaram-se quatorze categorias. Algumas apresentavam formas corretas de transmissão: através de contato físico e corporal do tipo "cabeça com cabeça”, com pessoas que têm Pediculose. Porém, outras revelaram o seu desconhecimento: o piolho voa, o piolho pula de uma cabeça para outra, através das lêndeas. Estes resultados demonstram a existência de professores que desconhecem a forma como a patologia é transmitida. Isto diminui a possibilidade que estes profissionais têm para colaborarem efetivamente na prevenção desta patologia nas escolas, assim como para a promoção da saúde de seus alunos.

Palavras-chave: Pediculose; transmissão; educação em saúde; Discurso do Sujeito Coletivo.

Estudo baseado na dissertação de mestrado: Educação em Saúde: Informação versus Mudança de Comportamento. Estudo da Pediculose sob o Olhar da Promoção da Saúde no Programa Saúde na Escola.

* Médica Pediatra e Neonatologista. Mestre em Ciências. E-mail: percide@uol.com.br

** Bióloga, Mestre em Medicina Veterinária. Pesquisadora do Laboratório de Educação em Ambiente e Saúde (LEAS) do Instituto Oswaldo Cruz / FIOCRUZ. E-mail: zeneida@ioc.fiocruz.br

Médico Pediatra. Professor Doutor. Chefe do Serviço de Pediatria do Hospital Universitário Gaffrée Guinle. E-mail: liberal@rio.com.br

**** Biólogo. Professor Doutor. Pesquisador do Laboratório de Educação em Ambiente e Saúde (LEAS) do Instituto Oswaldo Cruz / FIOCRUZ. Orientador no Curso de Pós-Graduação em Ensino em Biociências e Saúde do Instituto Oswaldo Cruz FIOCRUZ / RJ. E-mail: jub@ioc.fiocruz.br

Correspondência para: Júlio Vianna Barbosa. Av Brasil, 4365. Manguinhos, Rio de Janeiro, RJ, Brasil. CEP: $21045-900$. Telefone:2560-6474;2598-4378;Ramal125. E-mail: jub@ioc.fiocruz.br 


\begin{abstract}
:
Pediculosis is a public health pathology. Educational methods would certainly colaborate to the success of the treatment and prevention of this pathology. This study, developed in Rio de Janeiro's schools (RJ), Brazil, demonstrates the primary teachers' discourse on how pediculosis is transmitted. The pieces of information were obtained from interviews and analized by the Discourse of the Collective Subject method. Fourteen categories were revealed. Some correct ways of transmission were presented, for example: through physical and corporal contact, like "head to head", with people who have pediculosis. On the other hand, some of these categories revealed lack of knowledge about the subject: the lice fly; the lice jump from one's head to anothers'; through the nits. These results demonstrated that there are teachers that don't know about the transmission of this pathology. For this reason, the possibility that these teachers have to collaborate effectively to its prevention in schools diminishes; the same occurs with the health promotion of their students.
\end{abstract}

Key words: Pediculosis; transmission; health education; Discourse of the Collective Subject.

\section{INTRODUÇÃO}

A Pediculose é uma doença frequentemente encontrada no ambiente escolar. Esta patologia é causada pelo Pediculus humanus capitis e vem sendo combatida há muitos anos, através de medicamentos e outras medidas, como o uso do pente fino.

É sabido que a Pediculose, apesar dos esforços dos profissionais que se dedicam ao seu controle, principalmente os da saúde e educação, se mantém com prevalência alta em várias partes do planeta. Em Delhi, Índia, Khokhar $^{1}$ encontrou $16,59 \%$ de prevalência. Em Victoria, Austrália, esta foi de $13 \%^{2}$; e em Mersin, Turquia, 6,8\%. ${ }^{3}$ Em recente trabalho desenvolvido com escolares, em Uberlândia (MG) no Brasil por Borges e Mendes ${ }^{4}$, a prevalência chegou a 35\%. Estes autores também afirmam que o piolho da cabeça deve ser mais bem investigado regionalmente, pois acreditam que fatores sociais têm influência direta sobre a epidemiologia da doença.

Diante da importância desta patologia para a saúde pública, apesar da Pediculose da cabeça não estar diretamente relacionada à transmissão de outras patologias, como é o caso do piolho do corpo (Pediculus humanus humanus $)^{5}$, certamente é causadora de muito absenteísmo escolar ${ }^{6,7}$; logo, muitas medidas têm sido buscadas para o seu controle. Os piolhos têm mostrado importante resistência aos medicamentos mais usados pela população em geral. É provável que esta resistência tenha relação com a evolução e condução equivocada de alguns casos. ${ }^{8,11}$ Pollack, Kiszewshi e Spielman ${ }^{12}$ demonstraram em seu estudo que um terço dos casos apontados como Pediculose não correspondiam à patologia, mas a outros artefatos presos aos cabelos, como restos celulares. Assim sendo, ao lado do já referido absenteísmo escolar, encontra-se também o aumento da prevalência da patologia e do uso indevido de medicamentos. A pesquisa de substâncias capazes de controlar a Pediculose permanece como um desafio para a comunidade científica e novas medidas têm sido buscadas para o seu controle. Recentemente, Pearlman ${ }^{13}$ apresentou um trabalho sobre uma nova medicação atóxica, a qual causa asfixia e mata o inseto, mas outros ensaios ainda devem ser desenvolvidos para que esta possa ser utilizada em larga escala. 
Atualmente, apesar de muitos médicos prosseguirem prescrevendo medicamentos para o controle da Pediculose, as crianças continuam tendo piolho. Isto se dá pela resistência, já descrita, mas também pela elevada probabilidade de reinfestação no ambiente escolar e domiciliar. Desta forma, acredita-se que medidas educacionais devam ser tomadas para que a população consiga controlar melhor este problema. No ambiente escolar, os professores solicitam a realização de atividades educativas sobre Pediculose, na esperança de conseguir um maior esclarecimento de alunos e familiares, com consequente diminuição dos índices de infestação dos escolares.

Foi com base em uma solicitação de professores que, em 2003, desenvolveu-se uma atividade educativa sobre Pediculose para um Centro Integrado de Educação Pública (CIEP), localizado em São Gonçalo, na região metropolitana do Estado do Rio de Janeiro (RJ), Brasil. Esta atividade foi criada por um profissional de saúde, que pertencia à equipe de saúde desta escola, pois fazia parte de um programa de saúde escolar da Secretaria de Estado de Saúde e da Defesa Civil do Rio de Janeiro, o Programa Saúde na Escola (PSE).

Esta atividade de educação em saúde representou o objeto de pesquisa de um projeto da Pós-Graduação em Ensino em Biociências e Saúde (PG-EBS) do Instituto Oswaldo Cruz da Fundação Oswaldo Cruz (IOC/FIOCRUZ). Assim, o objetivo é prover a construção do conhecimento de alunos e professores, bem como relatar o saber prévio sobre Pediculose.

\section{MÉTODO}

Trata-se de trabalho com parte do discurso dos professores sobre Pediculose, antes do desenvolvimento da atividade educativa. Para este estudo, foram desenvolvidas entre- vistas em 4 escolas do estado do Rio de Janeiro, três Centros Integrados de Educação Pública (CIEP) e uma escola da rede particular de ensino da cidade do Rio de Janeiro. Sua escolha foi aleatória. Participaram, no total, vinte professores, do sexo feminino, que lecionam do primeiro ao $5^{\mathrm{a}}$ ano, os quais espontaneamente aceitaram colaborar com o projeto. Todos assinaram um termo de consentimento fornecido no ato da apresentação da pesquisa, onde o sigilo e anonimato foram garantidos. Nestas entrevistas foram feitas várias perguntas abertas sobre Pediculose, na busca de seu conhecimento sobre a patologia, antes da realização da atividade educativa, porém o presente trabalho dará ênfase às respostas referentes às questões: "Você sabe como se pega piolho? Por favor, explique”.

Trata-se de um trabalho descritivo cuja amostra foi intencional - em função da idade descrita como de maior prevalência da doença. As entrevistas foram gravadas e transcritas na integra. Sendo um estudo qualitativo, os resultados foram analisados pela técnica do Discurso do Sujeito Coletivo. ${ }^{14}$ Esta técnica visa a tornar mais clara uma dada representação social, bem como o conjunto das representações que conforma um dado imaginário. Isto é conseguido a partir do trabalho com todos os dados revelados nas entrevistas, por exemplo, onde nada é desprezado. O uso de tabelas denominadas instrumentos de análise de discurso, formadas para cada questão separadamente, permite que, da resposta do sujeito às questões das entrevistas, seja buscado o seu sentido. Este último, ao ser definido, forma a idéia central (IC) da resposta, enquanto que o que foi descrito na mesma, as "palavras do sujeito”, que representam este sentido, são a sua expressão-chave. A partir das diversas IC encontradas, busca-se agrupá-las para formar a IC síntese ou categoria, a qual representa as várias IC formadas de mesmo sentido, ou de sentidos complementares. As diferentes expressões-chave de uma IC síntese ou categoria irão 
então formar o discurso dos sujeitos que participaram do estudo: o Discurso do Sujeito Coletivo. Esta técnica dá ao pesquisador a possibilidade de trabalhar uma grande quantidade de dados, em função dos passos que devem ser seguidos, buscando a neutralidade do pesquisador com a sua forma objetiva de análise. Com isso, permite que as representações sociais sejam construídas e depois interpretadas.

\section{RESULTADOS}

Os resultados apresentados a seguir foram tabulados de acordo com as suas idéias centrais. Através das falas, identificou-se 45 idéias centrais. Estas foram agrupadas em 14 categorias, as quais serão apresentadas a seguir com os seus respectivos Discursos do Sujeito Coletivo (D.S.C.) para a questão: "Você sabe como se pega piolho? Por favor, explique”.

1a CATEGORIA: Através de contato físico e corporal do tipo "cabeça com cabeça”, com pessoas que têm Pediculose: Eu acho que é contato com outra pessoa que tenha piolho, pessoas que estejam com Pediculose. Contato direto, corporal, encostando, se agarrando. Contato físico de agarrar, de abraçar, de beijar. As crianças, uma em contato com a outra, aquele colega que está com piolho, ele está infestado, então, aquela criança que não tem, acaba passando, cabeça juntinha... Encostar a cabecinha, contato físico, eu acredito que ele passa de uma cabeça para a outra. Já peguei muito esse problema, quando eu tava trabaIhando com o C.A., crianças menores, eu usava nesse tempo cabelo grande, assim, preparado, elas encostavam em mim, vinham me dar, fazer carinho, e ficavam assim. No dia seguinte eu tava com a cabeça coçando.

$2^{\text {a }}$ CATEGORIA: Por objetos usados na cabeça, como pentes e bonés. Dormindo em travesseiros e lençóis, ou por toalhas: Pente, pelo pente! Se você usa, passa na cabeça um pente que você não sabe a procedência, um pente de terceiros, pode ter um piolhinho ou uma lêndea que caia. Utilizando coisas impessoais que está na cabeça da pessoa, pentes, bonés, objetos como toalha, travesseiro, dormindo no lençol, também pega!

$3^{\text {a }}$ CATEGORIA: De uma pessoa para a outra, através da convivência, quando se brinca com quem tem piolho, ou se dorme na mesma casa: Normalmente, o que nós como professoras ficamos sabendo, passa de um coleguinha para outro, de uma pessoa para outra. Eu acho que é possível, se uma pessoa, um adulto ou uma criança, estiver com piolho, e você chegar perto, pelo contato, você está correndo o risco de adquirir o piolho. A convivência de uma pessoa que não tem, com outra que tem, crianças, por exemplo, que têm piolho, convivem com outras crianças e pegam piolho. Esta convivência pode ser brincando na mesma casa, dormindo, através do contágio de um para o outro, estar junto o tempo inteiro, assim, brincando. Acho que sim, passa...

4 a CATEGORIA: Através de piolho que cai na cabeça, ou cai nas pessoas e sobe para a cabeça: Piolho, se cair próximo à criança, ele pode subir pela cabeça e fica ali. Eu acho também que sobe em mim, ou então que cai.

5a CATEGORIA: Através do vento: Através do vento. Eu já tive casos na sala de aula que a colega foi tirando, a garotinha foi tirando e botou em cima da mesa. Quer dizer, ventilador ligado, foi um transporte da cabecinha do outro.

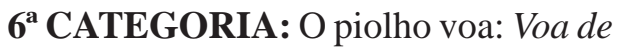
um cabelo pro outro.

$7^{\text {a }}$ CATEGORIA: O piolho pula de uma cabeça para a outra: Se um colega está com piolho e você está próximo dele, com certeza, este piolho pode pular. Uma criança que te- 
nha, em contato com as outras crianças, ele vai acabar pulando.

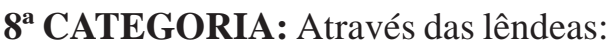
Encostar a cabeça em quem têm, através de, no caso, lêndea. Eu penso que é pelos ovinhos, que são as lêndeas, que pelo contágio de uma cabecinha com outra, aqueles ovinhos que se chamam lêndeas vão passando e se transformam em piolhos que vão reproduzindo.

9a CATEGORIA: Através da falta de higiene, poeira, sujeira: Higiene... Isso afasta a lêndea?!? Eu nunca li nada profundo não, mas acho que falta de higiene, a sujeira, poeira, falta de tomar um banho, não ter aquele cuidado de lavar a cabeça, aquele banho direitinho, então tem essa tendência de ter, estar com piolho. É desse modo que se pega piolho!

10 ${ }^{a}$ CATEGORIA: Quando a criança rola com cachorro: Quando ela rola com cachorro o tempo todo.

11 ${ }^{\text {a }}$ CATEGORIA: Quando a criança brinca com areia não tratada: Se a criança tem um habito de brincar muito com uma areia que não é tratada, própria pra uma criança.

12 ${ }^{\text {a }}$ CATEGORIA: Por facilidade do indivíduo com relação ao seu sangue: Eu não sei, a respeito, muito da questão também do sangue, porque eu já ouvi, a respeito de ter relação com o sangue. Tem pessoas que têm mais facilidade, mas desta parte aí eu já não tenho muito conhecimento.

13 ${ }^{\text {a }}$ CATEGORIA: Não sabe se pega pela lêndea ou pelo ar: Mas, ao certo, se pega por lêndea ou pelo ar, eu não sei.

14 ${ }^{\mathrm{a}}$ CATEGORIA: Não sabe como se pega piolho: Não.

\section{DISCUSSÃO}

Existem muitos mitos sobre a transmissão do piolho da cabeça, o que dificulta o seu processo de controle. Neste trabalho, quando as professoras foram questionadas se sabiam como se pega piolho - sobre a transmissão da pediculose - a análise das respostas originou 5 formas possíveis sendo 2 raras; 6 formas impossíveis; 1 sem comprovação científica e 2 que revelam o desconhecimento destes profissionais em relação ao tema.

As primeiras cinco categorias apresentam IC e DSC com formas possíveis de transmissão da Pediculose. A primeira corresponde a forma mais comum de transmissão da patologia: através de contato físico e corporal do tipo "cabeça com cabeça”, com pessoas que têm pediculose. Segundo Burgess ${ }^{15}$, para que a transmissão aconteça, é necessário que este contato seja prolongado. Apesar de não se especificar quanto tempo é necessário para tal, sabe-se que o inseto move-se do couro cabeludo para a região mais externa dos fios de cabelo e desta para uma outra pessoa. Somente os adultos e as ninfas de $3^{\circ}$ estágio têm capacidade de se transferir de um hospedeiro para outro. Burgess ${ }^{15}$ também relata, como revelado no D.S.C. da primeira categoria, que mulheres adultas são mais susceptíveis a pegar Pediculose, em função do seu trabalho - mais mulheres trabalham com crianças - ou da sua rotina em família-passam mais tempo com suas próprias crianças, de quem “pegam piolho”. Neste discurso a experiência de vida e trabalho com crianças infestadas foi fato importante que colaborou para a construção deste conhecimento.

Os pentes, as escovas de cabelo, chapéus, roupas de cama e de banho, assim como outros objetos podem portar um ou mais piolhos e assim, indiretamente, estes podem ser transferidos entre as pessoas. ${ }^{16}$ Estes dados coincidem com o DSC revelado na IC da segunda categoria: por objetos usados na cabeça, como pentes e bonés. Dormindo em travesseiros e lençóis, ou por toalhas. Para 
Ibarra e Hall ${ }^{17}$, o piolho pode ser retirado da cabeça em um movimento de pentear, sendo introduzido no cabelo novamente, no próximo movimento. Estes autores falam que a maioria dos piolhos não é lesada através do ato de pentear os cabelos, permanecendo assim, capazes de infestarem outros indivíduos, especialmente se o pente passar de uma pessoa para outra em curto espaço de tempo. Entretanto, Chunge et al. ${ }^{18}$ afirmam que o piolho da cabeça raramente sobrevive longe do hospedeiro por mais de 36 horas. Em seu estudo, estes autores observaram que o período máximo de vida destes insetos nestas condições foi de 55 horas. Para Burgess ${ }^{19}$ é pouco provável que ainda permaneçam capazes de infestar, à noite, no caso de terem se transferidos para o travesseiro pela manhã. Já a transferência de piolhos para travesseiros, à noite, é confirmada em outros trabalhos. ${ }^{20,21}$ Speare et al..$^{21}$ encontraram insetos viáveis, capazes de infestar novos indivíduos após 9 horas de permanência no travesseiro. Neste trabalho, os autores citam que, apesar de ser pequena a chance de se encontrar piolhos nos travesseiros e menor ainda em lençóis ou cobertores, existe a necessidade de se garantir a prevenção da transmissão da Pediculose, com lavagem destes objetos em temperaturas de $60^{\circ} \mathrm{C}$ ou maiores. Khokhar ${ }^{1}$ demonstrou que, a chance das crianças adquirirem a Pediculose se compartilharem a mesma cama e o mesmo pente, aumenta muito. Com base nos dados apresentados, é importante valorizar a possibilidade de transmissão via fômites.

A IC da $3^{\text {a }}$ categoria: de uma pessoa para a outra, através da convivência, quando se brinca com quem tem piolho, ou se dorme na mesma casa, apesar de revelar uma condição possível, o DSC indica uma relativa dúvida da professora quanto à forma de transmissão da patologia, sendo citado o contato e a convivência. Burkhart ${ }^{22}$ afirma que existem muitos outros modos de transmissão da Pediculose, não necessariamente relacionados ao contato direto de cabeça com cabeça. Estes, ainda que obscuros, devem ser elucidados para que a patologia venha a ser prevenida, entretanto, só a observação direta da forma como se dá esta convivência poderá colaborar para que a sua descrição seja feita e a forma com que sua prevenção deverá ser realizada, seja alcançada. Neste caso acredita-se que trabalhos que buscam o conhecimento dos profissionais da educação sobre a transmissão da pediculose em sala de aula podem colaborar para a elucidação destas formas obscuras, sugeridas pela literatura consultada.

Dentre as formas possíveis, porém raras, os DSC revelados foram: 1) através do vento.....; 2) piolho, se cair próximo à criança, ele pode subir pela cabeça e fica ali.... (respectivamente a $4^{\mathrm{a}}$ e a $5^{\mathrm{a}}$ categorias). Para Burgess $^{20}$, o piolho pode ser "lançado” à distância quando um indivíduo penteia seu cabelo. Por ser muito leve, pode ser carreado pelo vento. ${ }^{22}$ Mas, certamente, para que ocorra a transmissão da Pediculose através destes meios, o inseto lançado necessita cair sobre a cabeça, sobre a roupa ou a pele de outro indivíduo e então posteriormente subir para a sua cabeça. ${ }^{17}$ A pesquisadora ainda não vivenciou, em sua prática, situações semelhantes. Entretanto, muitas são as complexidades de sala de aula, assim como diversas são as situações enfrentadas pelos profissionais da educação em sua prática diária; logo, é possível que estes já tenham vivenciado momentos que justificam o conhecimento por elas apresentado nestes discursos.

Das IC e DSC que correspondem a formas impossíveis de transmissão da patologia, três assim o são em função das características anatômicas do piolho e da lêndea. As categorias são estas: o piolho voa, o piolho pula de uma cabeça para a outra, e, através das lêndeas. O piolho não pula, não tem asas e a lêndea fica fixada ao fio de cabelo por uma substância produzida pelo inseto, quitina, sendo inclusive 
difícil a sua retirada manual. ${ }^{23}$ Somado a isso, dificilmente o ato de pentear os cabelos leva uma lêndea a se desprender, e mesmo que isto aconteça, o local onde irá cair pode fazer com que se torne inviável e não libere a ninfa que está em seu interior. ${ }^{18}$ É possível que este conhecimento também esteja diretamente relacionado ao que foi apresentado, de acordo com a literatura pesquisada, na discussão das categorias 4 e 5: o piolho, por ser leve, pode ser "lançado" a distância. Isto pode se constituir em um fator criador do confundimento em relação à sua possibilidade de mobilização (poder voar ou pular) e conseqüentemente também a sua forma de transmissão.

É sabido que a Pediculose não é causada pela falta de higiene e esta não a predispõe. Pessoas que cuidam regularmente da sua higiene também adquirem a patologia, independente da sua classe social, sexo, raça e credo. ${ }^{5}$ Os piolhos não são eliminados por hábitos regulares de lavar e pentear os cabelos. ${ }^{8} \mathrm{~A}$ Pediculose não é transmitida por vetores e o piolho não vive em areia nem no chão, mesmo nas escolas. ${ }^{24}$ Speare, Thomas e Cahill ${ }^{25}$ demonstraram que o risco de transmissão do piolho através do chão de escolas é muito pequeno. Estes autores não encontraram qualquer piolho ou lêndea no chão das salas de aula onde crianças com Pediculose estudavam. Logo, as categorias: através da falta de higiene, poeira, sujeira; quando a criança rola com cachorro e quando a criança brinca com areia não tratada ( $9^{\mathrm{a}}, 10^{\mathrm{a}}$ e $11^{\mathrm{a}}$ respectivamente), revelam DSC compostos por formas impossíveis de transmissão da pediculose. A questão da relação direta entre ter a pediculose e não ter boa higiene é fato inquestionável e possivelmente um conhecimento adquirido de difícil descontinuação. Porém, para famílias que enfrentam outros problemas tão mais prementes (alimentação, habitação, segurança e outros), a pediculose passa a ter importância secundária ${ }^{26}$, e isto pode ser julgado como "falta de higiene". Não foi objetivo deste trabalho, mas é possível que este conhecimento tenha sido estabelecido em função das condições de vida dos alunos atendidos por este grupo de profissionais entrevistados, o que reflete mais uma vez a inquestionável complexidade do dia-a-dia dos mesmos, convivendo com indivíduos que precisam "fazer escolhas seletivas" sobre o que devem ou não priorizar. Situação bastante danosa quando se está fazendo referência a uma patologia que apresenta conseqüências potencialmente graves para a saúde dos que estão por ela acometidos.

A $12^{a}$ categoria: por facilidade do indivíduo com relação ao seu sangue, ainda não tem comprovação científica. ${ }^{27}$ As categorias: não sabe se pega pela lêndea ou pelo ar, e, não sabe como se pega piolho $\left(13^{\mathrm{a}}\right.$ e $\left.14^{\mathrm{a}}\right)$, revelam DSC constituídos pelo desconhecimento destes profissionais em relação ao tema. Estas respostas certamente apresentam a urgência com que se necessita desenvolver atividades educativas em saúde para profissionais da educação. Price et al. ${ }^{6}$, assim como Khokhar ${ }^{1}$, sugerem esta forma de trabalho, em seus estudos, o que vem mostrar como é importante para os educadores, o fato de conhecerem as formas possíveis de transmissão desta patologia.

Os equívocos no diagnóstico da Pediculose são descritos na literatura; existem profissionais da saúde e outros que também fazem diagnósticos equivocados da patologia. ${ }^{12}$ Paralelamente, os resultados aqui demonstrados revelam outra condição ligada à patologia: existem professores que lidam com crianças que têm piolho, mas apesar disso, desconhecem as suas formas de transmissão. A formação destes profissionais possivelmente não contempla várias situações que porventura venham a enfrentar na dinâmica do seu dia-a-dia de trabalho. No entanto, é importante que os mesmos tenham conhecimento das formas possíveis de transmissão da pediculose (assim como de outras patologias prevalentes no ambiente escolar) para poder prevenir a sua transmissão em sala de aula e com isso estar cola- 
borando também para a promoção da saúde dos alunos.

Não está sendo sugerido que o professor, então, assuma mais uma responsabilidade em sua trajetória diária: a que contemple o papel de um profissional da saúde na sua essência. Mas sim, que estes profissionais da educação possam vir a ser empoderados no que se refere a algumas patologias prevalentes em seu ambiente de trabalho, para que seus objetivos sejam mais facilmente alcançados.

Especificamente em relação a pediculose, dados sobre a relação da transmissão com o comportamento adotado pelo indivíduo, assim como a desvinculação da relação direta entre "ter ou não higiene” e "ter piolho" são algumas das informações essenciais para que a transmissão do inseto seja entendida e controlada.

Desta forma, de acordo com os resultados apresentados neste trabalho, torna-se evidente a necessidade de se auxiliar os professores para a construção do conhecimento sobre esta patologia. Isto é possível. Especificamente sobre pediculose, no Laboratório de Educação Ambiente e Saúde (LEAS) / Instituto Oswaldo Cruz / FIOCRUZ / RJ, é oferecido um curso de formação para professores e outros profissionais da saúde e/ou educação com interesse no tema. Ao participarem das atividades educativas específicas oferecidas no curso, os profissionais têm contato com materiais sobre a patologia, podem observar estes insetos ao microscópio e trocar muitas de suas experiências com os especialistas, coordenadores do curso, o que certamente também colabora para o aprimoramento das atividades educativas desenvolvidas no LEAS. As informações são apresentadas através de metodologia capaz de colaborar para a construção do seu conhecimento, possibilitando o surgimento e o fortalecimento de um pensamento crítico sobre o assunto de ambas as partes.
A escola deve ser um ambiente seguro e saudável, onde o desenvolvimento de crianças e adolescentes possa se dar de forma efetiva, com o alcance do máximo de seus potenciais intelectuais, sem danos psicológicos e/ou físicos. ${ }^{28} \mathrm{Ne}-$ gar que a pediculose é uma patologia por vezes tão presente em sala de aula que pode ser capaz de alterar não só o rendimento escolar de alunos infestados, quanto fazer surgir alterações psicológicas capazes de desestruturar famílias inteiras, é negar a sua existência. O enfrentamento deste problema por parte dos professores pode ser alcançado, assim como uma formação cidadã, nos quais, mitos e outras crenças sejam desconstruídos, dando lugar a novos caminhos que possibilitem a interrupção da perpetuação da transmissão desta patologia em sala de aula. $\mathrm{O}$ professor precisa ter segurança em comentar o tema em sala de aula e com isso também ter a oportunidade de intervir junto às famílias e à escola, no sentido de tentar minimizar o sofrimento dos seus alunos, combaterem o bullying, colaborando para a promoção da saúde de todos. A criação de habilidades pessoais, o reforço à ação comunitária e a criação de ambientes favoráveis á saúde são três dos cinco campos de ação da promoção da saúde que podem ser contemplados pela escola em relação à pediculose, quando novas perspectivas acerca da educação em saúde sobre o tema são observadas.

Assim sendo, esta pesquisa vem trazer informações novas não só sobre parte da realidade das salas de aula como também sobre um caminho que os professores têm para obter informações sobre o tema; já que, apesar destes profissionais não terem a responsabilidade de ensinar formalmente sobre esta patologia, não há como negar que o seu conhecimento influenciará na forma como as ações serão adotadas na comunidade escolar e como poderão ou não colaborar para a promoção da saúde nos seus locais de trabalho e também “extra-muros”. 


\section{REFERÊNCIAS}

1. Khokhar A. A study of Pediculosis capitis among primary school children in Delhi. Ind. J. Med. Sciences. 2002; 56(9):449-452.

2. Counahan M, Andrews R, Büttner P, Bymes G, Speare R. Head lice prevalence in primary schools in Victoria, Australia. J. Paediatr. Child. Health. 2004; 40:616-19.

3. Kokturk A, Baz K, Bugdayci R, Sasmaz T, Tursen U, Kaya TI, et al. The prevalence of Pediculosis capitis in schoolchildren in Mersin, Turkey. International Journal of Dermatology 2003; 42:694-98.

4. Borges R, Mendes J. Epidemiological aspects of head lice in children attending day care centers, urban and rural schools in Uberlândia, central Brazil. Mem. Inst. Oswaldo Cruz. 2002; 97(2):189-92.

5. Barbosa JV; Pinto ZT. Pediculose no Brasil. Entomol. Vect. 2003; 10(4):57986.

6. Price JH, Burkhart CN, Burkhart CG, Islam R. School nurses’ perceptions of and experience with head lice. J. Sch. Health. 1999; 69(4):153-58.

7. Ressel GW. AAP releases clinical report on head lice. Am. Fam. Physician. 2003; 67(6):1391-92.

8. Rupes V, Moravec J, Chmela J, Ledvinka J, Zelenková J. A resistance of head lice (Pediculus capitis) to permethrin in Czech Republic. Centr. Eur. J. Publ. Hlth. 1995; 3(1):30-2.

9. Downs AMR, Stafford KA, Harvey I, Coles GC. Evidence for double resistence to permethrin and malathion in head lice. British Journal of Dermatology 1999; 141: 508-511.

10. Meinking TL, Serrano L, Hard B, Entzel P, Lemard G, Riviera E, Villar ME. Comparative in vitro pediculicidal efficacy of treatments in a resistant head lice population in the United States. Arch Dermatol. 2002; 138:220-4.

11. Hunter JA, Barker SC. Susceptibility of head lice (Pediculus humanus capitis) to pediculicides in Australia. Parasitol. Res. 2003; 90:476-78.

12. Pollack RJ, Kiszewshi AE, Spielman A. Overdiagnosis and consequent mismanagement of head louse infestation in North America. Pediatr. Infect. Dis. J. 2000; 19(8):689-94.

13. Pearlman DL. A simple treatment for head lice: dry-on, suffocation-based pediculicide. Pediatrics. 2004; 114:275-79.

14. Lefèvre F, Lefèvre AMC. O Discurso do Sujeito Coletivo: um novo enfoque em pesquisa qualitativa (Desdobramentos). Caxias do Sul: EDUCS, 2003.

15. Burgess I. The life of a head louse. Nursing Times. 2002; 98(46):54.

16. Heukelbach J, Feldmeier H. Ectoparasites - the underestimated realm. The Lancet. 2004; 363:889-91.

17. Ibarra J, Hall DM. Head Lice in schoolchildren. Arch. Dis. Child. 1998; 78:288.

18. Chunge RN, Scott FE, Underwood JE, Zavarella KJ. A pilot study to indicate transmission of head lice. Canadian Journal of Public Health 1991; 82:207-8.

19. Burgess IF. Human Lice and their control. Annu. Ver. Entomol. 2004; 49:457-81.

20. Burgess IF. Human Lice and their management. Advances in Parasitology. 1995; 32:271-342.

21. Speare R, Cahill C, Thomas G. Head Lice on pillows, and strategies to make a small risk even less. Int. J. Dermatol. 2003; 42:626-29.

22. Burkhart CN. Fomite transmission with head lice: a continuing controversy. The Lancet. 2003; 361:99-100. 
23. Behrman RE, Kliegman RM, Jenson HB. Creches e Doenças Transmissíveis. In: Behrman RE, Kliegman RM, Jenson HB. Nelson. Tratado de Pediatria. $17^{\mathrm{a}}$.ed. Rio de Janeiro: Elsevier; 2005. v.1. p.1266-1269.

24. Roberts RJ. Head Lice. N. Engl. J. Med. 2002; 346(21):1645-50.

25. Speare R, Thomas G, Cahill C. Head lice are not found on floors in primary school classrooms. Australian and New Zealand Journal of Public Health. 2002; 26(3):208-11.
26. Hootman J. Quality Improvement projects Related to Pediculosis Management. The Journal of School Nursing. 2002; 18(2):80-86.

27. Borges R, Mendes J, Valladares BLB. Invasores da Cabeleira. Ciência Hoje das Crianças 2003; 16(34):2-5.

28. Lopes Neto AA. Bullying comportamento agressivo entre estudantes. Jornal de Pediatria. 2005; 81 Supl 5:S164-S172.

Recebido em: 28/08/2008 Modificado em: 30/09/2008 Aceito em: 22/11/2008 